\title{
Um esboço de um programa weberiano para compreender o Pentecostalismo
}

Brand Arenari'

\section{Resumo}

Neste trabalho, procuro mapear os impedimentos históricos e ideológicos e também as possibilidades da construção de um programa de pesquisa teórico e empírico organizado a partir das ideias de Max Weber a respeito de um fenômeno religioso o qual este autor não presenciou, a saber, o Pentecostalismo. Tendo em vista tal objetivo, construirei meus argumentos em quatro eixos distintos: ( 1 ) "O Mainstream da análise do Pentecostalismo e o afastamento da perspectiva weberiana"; (2) "Max Weber e o Materialismo"; (3) "Pentecostalismo e o Capitalismo"; (4) "A promessa de salvação para uma nova classe na história"; e, por último, (5) "Notas a respeito da cognição religiosa e o Pentecostalismo". Ao término deste artigo, não tenho a pretensão de apresentar uma tese final sobre o Pentecostalismo, mas sim, um conjunto de hipóteses bem sólidas, aos moldes de um programa de pesquisa a ser desenvolvido e testado.

Palauras-chave: Max Weber. Pentecostalismo. Sociologia da Religião.

\section{Introdução}

Neste trabalho, procuro mapear os impedimentos históricos e ideológicos e também as possibilidades da construçáo de um programa de pesquisa teórico e empírico organizado a partir das ideias de Max Weber a respeito de um fenômeno religioso o qual este autor não presenciou, a saber, o Pentecostalismo. Tendo em vista tal objetivo, construirei meus argumentos em quatro eixos distintos: (1) "O Mainstream da análise do pentecostalismo e o afastamento da perspectiva weberiana"; (2) "Max Weber e o Materialismo";

\footnotetext{
É doutor em sociologia pela universidade Humboldt de Berlim. Possui graduação em Ciências Sociais pela Universidade Estadual do Norte Fluminense Darcy Ribeiro e mestrado em Cognição e Linguagem pela Universidade Estadual do Norte Fluminense Darcy Ribeiro.Tem experiência na área de Sociologia, com ênfase em Sociologia da religião e teoria social.
} 
(3) "Pentecostalismo e o Capitalismo"; (4) "A promessa de salvação para uma nova classe na história"; e, por último, (5) "Notas a respeito da cognição religiosa e o pentecostalismo”. Ao término deste artigo, não tenho a pretensão de apresentar uma tese final sobre o Pentecostalismo, mas sim, a despeito da linguagem ensaística, pois se trata da reorganização de uma apresentação oral, um conjunto de hipóteses bem sólidas, aos moldes de um programa de pesquisa a ser desenvolvido e testado.

\section{O Mainstream da análise do pentecostalismo e o afastamento da perspectiva weberiana}

Nas últimas páginas do livro A Ética Protestante e o Espirito do Capitalis$m o^{2}$, Max Weber escreve em tom pesaroso sobre o destino do nosso mundo. Weber manifestava seu pessimismo sobre o avanço da sociedade capitalista e sua crescente racionalização, vaticinando em linhas nietzschianas que esta sociedade poderia transformar os homens em "Especialistas sem Espírito e hedonistas sem coração $0^{3 "}$. Porém, no mesmo parágrafo, ele afirma que ninguém pode prever o futuro, ninguém sabe se "novos profetas" vão surgir no final desse processo, ou se haverá um retorno a "velhas ideias e crenças antigas". A verdade é que Max Weber não pode perceber, porque isso ainda era incipiente no seu tempo, mas muitos desses "novos profetas" que apareceriam nas entranhas daquele "velho mundo" eram de fato, seus contemporâneos ${ }^{4}$.

O impacto dessas novas ideias e desses novos profetas somente ficou claro aos nossos olhos no final do século XX. Eles não destruíram completamente as forças daquele mundo que Weber tinha falado, nem podemos afirmar que essas ideias fizeram o mundo melhor ou até mesmo impediram a produção de especialistas sem espirito e hedonistas sem coração. No entanto, essas ideias foram

\footnotetext{
Dieprotestantische Ethikundder Geistdes Kapitalismus.

Fachmenschen ohne Geist, Genußmenschenohne Herz.

4 Refiro-me aqui ao final do século XIX e inicio do século XX, onde uma série de novas ideias religiosas surgiu nos Estados Unidos, o que veio a ser conhecido como o movimento de New Thought. Paralelamente a este conjunto de ideias, há também a famosa Christian Science. O núcleo básico dessas ideias que caracteriza este movimento gira em torno da noção de que o homem pode curar doenças através do poder da mente. No entanto, os conceitos dos efeitos do pensamento positivo - lei da atração, cura, força de vida, visualização criativa e poder pessoal - são parte disso e têm evoluido ao longo do tempo e serviram de base para as teologias orientadoras do movimento New Age e do Pentecostalismo.
} 
capazes de dar uma nova forma ao processo de radicalização da racionalização, trazendo para dentro da esfera religiosa uma ruptura com o racionalismo, que desde então marcou a tendência dos principais movimentos religiosos do ocidente no final do século XX e início do século XXI.

Nos finais dos anos 1970, todos nós presenciamos uma "revolução" no campo religioso e o desmoronamento de algumas de nossas antigas crenças sociológicas a respeito do tema. Uma gama de novas religiosidades, que não cabiam no script traçado pelas velhas teorias, apareceram. Surpreendeu a muitos a força e visibilidade de novas religiosidades no ocidente, a saber, o conjunto de crenças e práticas mágico-místico- religiosas difundido a partir da costa oeste dos EUA, em que orientalismo, mentalização, pensamento positivo, espiritualismo entre outros elementos foram reunidos, e que chamamos de religiosidade New Age. Assim também como sua versão para as classes pobres da expansão moderna, i.e., o Neopentecostalismo. Essas duas novas formas de religiosidade são os pontos de maior destaque nessa transformação que mencionamos.

A eclosão de ideias a respeito dessas novas formas de experiência religiosa tomou corpo em uma variedade de nomes, refletindo, em parte, a variedade das interpretaçóes. Passamos a chamar esse novo "incômodo" de "Retorno do Sagrado", "virada Espiritual" (Spiritual Turn), "Vingança de Deus", "Retorno das Religiōes", "reencantamento do mundo" entre outros menos conhecidos. Todos esses nomes, apesar de sutis diferenças interpretativas convergem para um ponto central, o reconhecimento dos limites, e alguns fracassos do paradigma teórico da teoria da secularização.

Tomando esse quadro descrito como exemplo, poderíamos considerar que a herança weberiana sobre a religiāo no século XX concentrou seus esforços de análise apenas na primeira parte do que narramos inicialmente, ou seja, aquela que falava a respeito do destino trágico incontornável que o processo de racionalização nos legaria, abandonando a possibilidade do surgimento de novos profetas e novas ideias. $\mathrm{O}$ resultado disso foi que se reelaborou e difundiu a famosa teoria da secularização como principal braço da tradição weberiana. Com o desgaste deste paradigma, Weber e as categorias weberianas do pensar também foram deixados de lado como base fundamental para interpretar os novos fenômenos religiosos. 
A visão sociológica dominante sobre religião atualmente, e, consequentemente, sobre o Pentecostalismo, está correlacionada com a mudança paradigmática que podemos chamar de culturalismo, a qual se iniciou, mais claramente, nos anos 1980, com destaque para a obra de Stuart Hall. Essa mudança negligenciou as causas "materiais" do desenvolvimento da religião, distanciando-se das explicaçôes funcionalistas para valorizar aspectos "imateriais" da cultura.

No caso específico de análise sociológica, o paradigma então dominante da teoria da secularizaçáo foi substituído pelos novos paradigmas de estudos culturais. Assim, aos poucos, ideias baseadas nos chamados estudos culturais e seus derivados, como a noção de multiculturalismo, o surgimento de novas identidades na açáo coletiva, e dos estudos pós-coloniais, em que autores como Homi Baba e Edward Said obtiveram destaque, foram ocupando o espaço nas interpretaçóes sobre religião. Estes estudos dirigiram a nossa atenção para a singularidade de grupos culturais na sociedade, levando-nos a abandonar a noção de grandes narrativas para entender o fenômeno de novas identidades e tradiçóes referentes a essências culturais. A ideia de um enfraquecimento da religiáo foi perdendo força, assim como o conceito de religiáo como uma nova forma de identidade coletiva, tornou-se forte e dominante (BURITY, 1997).

O surgimento de "estudos culturais" influenciou marcadamente a análise do fenômeno do retorno das religióes, especialmente a análise do pentecostalismo. Assim, podemos afirmar que, "o retorno da religiáo" foi interpretado como um fenômeno que atestou o que poderíamos chamar o "Retorno do culturalismo" para o núcleo central de análise nas ciências sociais, em contrapartida ao declínio do materialismo. Nesta parte, as ideias de estudiosos importantes do Pentecostalismo, como David Martin (2002), Walter Hollenweger (1972), Allan Anderson (1999), e Paul Freston (2001) se desenvolveram em sintonia com as principais ideias presentes no que poderíamos chamar "estudos culturais".

Por outro lado, as velhas teorias funcionalistas, as quais buscaram explicaçóes em fatores externos à religiáo, relacionadas a profundas mudanças socioestruturais, tais como: migraçôes, urbanização etc. estavam fortemente relacionadas aos velhos paradigmas da teoria da modernização. Essa visão originada dentro da velha teoria da modernizaçáo, especialmente a teoria da 
secularização e seu evolucionismo não foram capazes de dar respostas convincentes sobre o Pentecostalismo, e caíram em franco desuso. A partir desse olhar restrito da obra de Weber, este se tornou velho para entender o novo; mas, Weber é muito maior do que a herança apresentada na teoria da secularização, sua análise sobre as religióes transcendem este quadro.

\section{0 "materialismo" weberiano e a religião}

O primeiro passo para reconectar a herança weberiana à análise do Pentecostalismo remonta a percepção da existência de um "materialismo" weberiano, como também uma teoria de classe e grupos sociais relacionados à religião. No caso de Weber, não há apenas a tentativa de unir a classe social e cultura, como uma antecipação do pensamento bourdiesiano, mas também há a presença de uma análise que leva em conta a relaçáo entre a classe social, ou melhor, os estratos sociais e religião. No entanto, Weber foi de certa forma vítima do sucesso das ideias marxistas e dos impactos políticos do pensamento marxista. Em um mundo dividido entre comunistas e capitalistas, Weber foi elevado à categoria de um antimarxista, e foi interpretado erroneamente como um culturalista em oposição ao materialismo marxista. Como a teoria de Weber sobre o capitalismo iria ser erroneamente interpretada como uma confirmação do domínio da cultura sobre o materialismo, a religião logo apareceu no trabalho de Weber meramente como um produto da cultura.

No entanto, é no trabalho de Weber que podemos encontrar os primeiros indícios da relação teórica entre classe social e religião. $\mathrm{O}$ modelo de compreensão da religião que foi elaborado por Weber sempre esteve ancorado em bases materiais das classes sociais, eram as classes sociais as portadores (Trägerschitcher) de um tipo específico de religiosidade (WEBER, 1988).

Em sua análise, a despeito de interpretaçóes apressadas, Weber coloca a propriedade como uma categoria básica das distinçóes de classe (aqueles com e sem), bem como a localização do indivíduo no mercado de trabalho, ou seja, quais os tipos de serviços que esses indivíduos podem oferecer neste mercado. Em uma definição geral, Weber menciona que a classe social é configurada como resultado da situação de mercado. A partir dessa noção, Weber sempre buscou associar determinados grupos que ocupavam papéis em atividades de produção ou lugar de classe e status semelhantes a predisposiçóes 
cognitivo-religiosas. Boa parte de suas teses em sociologia da religião se baseiam nestas premissas. Assim, Weber descreveu o tipo-ideal camponês como marcado por certo tipo de relação de dependência absoluta e submissão à natureza, o que de certo modo moldava um modelo de religiosidade marcantemente mágica. Em outros momentos, Weber descreve:

[...] o confucionismo foi a ética civil de prebendários literatos formados em um racionalismo mundano [...]. O hinduísmo antigo, no entanto, foi conduzido por uma casta hereditária de especialistas treinados na escrita. [...] O Budismo foi difundido por frades mendicantes e itinerantes, estritamente contemplativos, que rejeitavam o mundo. [...] O Islã, em seus primeiros tempos, foi uma religião de guerreiros conquistadores. [...] O Judaísmo foi desde o exílio a religião de um "povo pária” burguês. [...] O Cristianismo começou sua jornada como uma doutrina de artesãos itinerantes. (1988, p. 240-24I, tradução nossa) $)^{5}$.

Essas associaçóes entre estratos da sociedade e a adoção de modelos cognitivos e certas religióes podem ser vistos no sistema elaborado pelo sociólogo weberiano Hans Peter Müller (2007). Ele sistematizou as associaçóes feitas por Weber entre religióes e estratos sociais, relacionando a ideia de classes sociais com a ideia de visóes de mundo e agência no mundo, condensados em aspectos religiosos.

Pierre Bourdieu desenvolveu muitos aspectos da sociologia de Weber em seus trabalhos, em especial da sociologia da religiáo. Entre os muitos avanços feitos pela sociologia de Bourdieu, no que se refere à questáo específica da religiáo, vale destacar suas ideias a respeito de como o habitus de classe gera tendências cognitivas de classe, i.e., gera disposiçóes cognitivo-religiosas de classe.

5 [...] so war der Konfuzianismus die Standesethik einer literarische gebildeten weltlisch-rationalitisten Pfründnerschaft [...]. Der ältere Hinduismus wurde dagegen getragen von einer erblichen Kaste literarische Gebildeter [...] Der Buddhismus wurde von Heimatlos wandernden, streng kontemplativen und weltablehnenden Bettelmönchen propagiert [...] Der Islam war in deiner ersten Zeit eine Religion welterobernder Krieger [...]. Das Judentum war, seit dem Exil, die Religion eines bürgerlichen Pariavolkes [...]. Das Christentum endliche begann seinen Lauf als eine Lehre wandernder Handwerksburschen. 


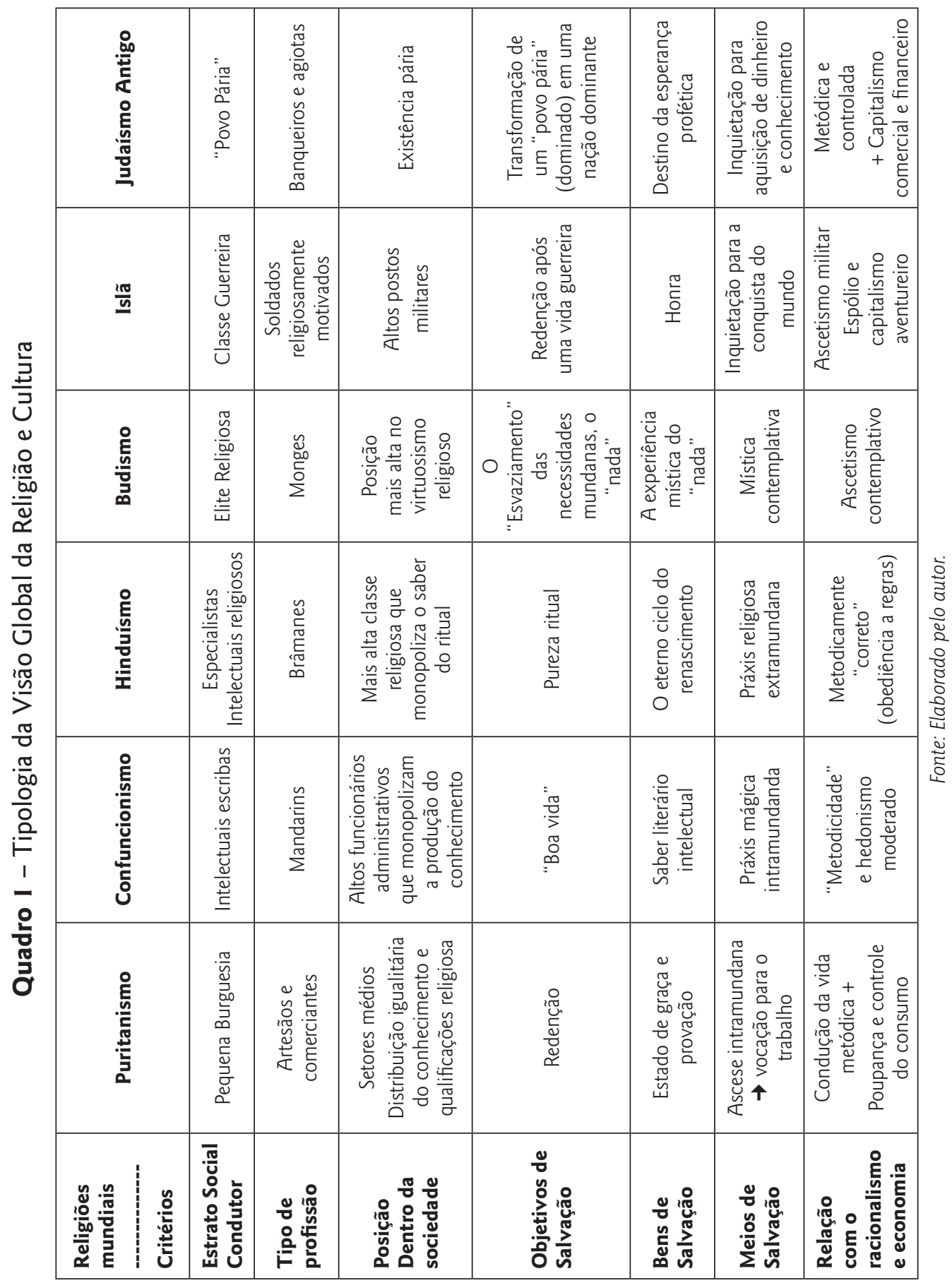


O principal ponto a ser discutido aqui se refere à ideia de que a estrutura das classes sociais - o que implica a incorporação, a maior parte das vezes inconsciente de um universo específico de classe - gera modelos gerais cognitivos de percepção do mundo (Weltanschauungen) dentro destas classes sociais. Estes modelos cognitivos de classe conduzem a uma série de disposiçóes específicas em relação à vida, que vão desde gostos específicos para determinados alimentos, música, artes visuais e literatura, criando certas disposiçôes estéticas em geral, que também englobam opinióes e ideias (BOURDIEU, 2002). Estes modelos engendram diferentes linguagens e tendências entre as classes no que diz respeito ao lidar como transcendental, formando, assim, disposiçôes religiosas específicas de classe. Também é interessante notar que na maioria dos casos, o núcleo desses modelos cognitivos é apresentado na forma de crenças e disposições religiosas, em seu coração estão os valores últimos que moldam as açôes de um determinado grupo social. Assim, a análise da religião torna-se um lugar privilegiado para a compreensão de certas classes sociais. Logo, o objetivo é demonstrar como as estruturas cognitivas, especialmente disposiçôes religiosas, estão conectadas a grupos sociais ou de classe social. Por sua vez, esstes movimentos religiosos ou essas disposiçóes religiosas são uma forma de expressão de classe.

Em tom conclusivo desta parte, podemos considerar que a religião é ao mesmo tempo um produto de interações sociais de um grupo social específico - o que envolve também as suas condiçóes materiais - mas por outro lado a religião modela esses grupos. Assim, uma nova religião ou religiosidade emerge da necessidade de um novo grupo social (ou classe social), o qual busca novas linhas cognitivas que possam dar sentido aos seus dramas específicos (desafios) de classe ou grupo - esta missão não pode ser desempenhada por um velho discurso religioso, que foi gerado para resolver o drama de outros grupos sociais -, de forma dialética, a resposta religiosa para esse drama específico muda e reconstrói a natureza do drama e da trajetória social desses grupos.

Mais uma vez, podemos ver que a noção de função social da religião, tal qual desenvolvida por Luhmann (1977), postulado aqui está dentro das linhas weberiana e de Pierre Bordieu, sem uma fronteira demarcada entre elas. A religião é uma resposta para dramas existenciais coletivos, oferecendo um sentido para eles (linha weberiana), como também é uma arma para lutar na 
disputa social pelo domínio da boa vida ou uma vida legitimada (linha Pierre Bordieu que também está presente em Weber). Mas, em ambas as linhas, a religiáo ou o caminho da transcendência também é resultado de aspectos cognitivos (limites cognitivos) da posição de classe (Klassenlage) e ou classe social (habitus de classe).

Apoiado por essas ideias, podemos compreender a função social da religião não apenas como o elaborador de uma identidade de grupo que é separado de outros aspectos da vida social, como afirmam as teorias contemporâneas sobre a religião que definem que a religião tem substituído as velhas formas de identidade coletiva (BURITY, 1997), mas para ver como a religião desempenha algumas funções importantes na dinâmica social como um todo. Nesse sentido, a religião não substitui a classe social, mas é parte importante na elaboração de uma identidade específica de classe ou de grupo. Em alguns momentos, a religião ou o discurso religioso não é um fuga para formar uma identidade coletiva em um mundo onde a classe social supostamente desapareceu, mas é uma forma dominante de linguagem ou comunicação específica em um tipo de posição social ou de classe. A religião opera principalmente na elaboração de um discurso integrado que garanta uma história ou uma sensação de drama coletivo de classe social por meio da linguagem religiosa. Assim, como Weber demonstrou em seus trabalhos, a história da luta de um Pariavolk (judeus) para sobrevivência social é transformada em uma teodiceia religiosa, tal teodiceia garante um sentido (moral) para esta luta, e ao mesmo tempo, legitima o modo de vida daquele povo ou grupo social. Nos tempos modernos, a religião opera em semelhante papel na luta de classes, ela oferece o aparato simbólico para legitimar o estilo de vida desta classe, assegurando a sobrevivência do grupo social, como também é uma arma para lutar por um bom lugar na sociedade. Assim, a luta da classe dos subintegrados da sociedade moderna para se integrar nesta sociedade e para legitimar o modo de vida de sua classe é transformada em uma jornada religiosa através do Pentecostalismo.

Assim, a partir do que foi exposto nesta seção, temos a primeira hipótese weberiana para a compreensão do Pentecostalismo. O Pentecostalismo, enquanto o terceiro movimento importante da Reforma Protestante está relacionado com a ascensão de uma classe social específica. $\mathrm{Na}$ modernidade, a cada 
surgimento de uma nova classe social, especialmente quando se trata de uma luta pelo reconhecimento social e integração na sociedade, estava ancorado no desenvolvimento de uma religião específica. Essa nova religiáo desempenha um papel na unificação do discurso e defesa dos valores e estilo de vida desta nova classe social que busca seu espaço na sociedade. Foi assim que a burguesia em harmonia com a teologia e as formas de expressão do Calvinismo pôde se afirmar. Da mesma forma, podemos apontar para o proletariado e o metodismo, e as formas em que este movimento religioso está fortemente relacionado coma ascensáo da classe trabalhadora. A mesma relação ocorre entre o pentecostalismo e as massas de pessoas que estão subintegradas ao sistema capitalista. O Pentecostalismo tem sido, desde seu início, a forma de expressão por excelência desses estratos sociais esquecidos pela análise sociológica.

\section{Pentecostalismo, Capitalismo e os Tipos Sociais}

Em todos seus estudos sobre as religiōes, seja sobre o judaísmo antigo ou o hinduísmo antigo, e especialmente o calvinismo, o olhar sobre as formas de vida religiosa estavam visceralmente interligados com uma análise de economia política, observando, sem uma linearidade mecânica causal, as relações entre as formas de produção e vida social e as formas de vida religiosa (WEBER, 1988). Jamais na obra de Weber a religião apareceu como produto de culturas ou heranças culturais específicas deslocadas do mundo concreto. Vale lembrar que, no caso específico do Pentecostalismo, pesa o fato de surgir em um tempo em que a esfera econômica desfruta de uma autonomização e dominância sem precedentes na história, muito diferente do período do surgimento do calvinismo. Sendo assim, um olhar weberiano sobre o pentecostalismo é preciso ser feito a partir da observação das afinidades eletivas existentes entre a força estruturante de nosso mundo, o capitalismo, e a religiáo.

No caso do pentecostalismo, recentes trabalham demonstram que esta é uma religião composta principalmente de populaçóes pobres que vivem em países em desenvolvimento, por mais que existam variaçóes, estáo são exceções (ROLIM, 1995; BERGER, 2014). Porém, não há muitos estudos que exploram esses dados associando este fenômeno a partir de uma perspectiva mais teórica. Como dados gerais sobre o Pentecostalismo, podemos destacar: (1) é uma religião da periferia do sistema capitalista, quase inexistente em países com altos níveis de igualdade, como é o caso da Europa Central, e sua força 
expansora se encontra principalmente na América Latina e África ${ }^{6}$; (2) é uma religião hegemonicamente urbana, mesmo na África sua expansão ocorre nas cidades, mais especificamente é uma religiâo da periferia urbana ${ }^{7}$; 3 ) é uma religiáo dos pobres, com poucos anos de estudo, número maior de mulheres, de mulatos, índios e negros ${ }^{8}$. Isto é, uma religiāo das classes dominadas da sociedade global atual.

Com isso em mente, podemos rever as explicações funcionalistas sobre pentecostalismo (abandonando a visão da velha Teoria da Modernização) e reinterpretá-la a partir das noçóes de Jesse Souza sobre Modernização periférica. Entender os outros caminhos da modernidade e os tipos sociais gerados nestes modelos de sociedade passam a ser decisivos em uma compreensão do Pentecostalismo a partir de matrizes do pensamento weberiano. Na sociologia da religiáo de Weber, as religióes foram interpretadas pari passo com os modelos de sociedade e os tipos sociais que portavam essas religióes; desse modo, seria imprudente querer entender o Pentecostalismo sem ao lado disso compreender o modelo de sociedade que, por profundas afinidades eletivas, serve de cenário, suporte e berçário do Pentecostalismo.

O traço mais marcante da modernização periférica que mais nos interessa aqui foi o fato que: se por um lado essas sociedades incorporaram plenamente as principais instituiçôes da modernidade, tais como um Estado Liberal e um Mercado plenamente desenvolvido, que regulam e avaliam as posiçóes dos indivíduos na sociedade, aliado a um forte discurso de ascensão e mobilidade individual; por outro lado, não incorporou um traço marcante da estrutura social das modernidades centrais, a saber, altos níveis de igualdade ou a incorporação do valor da igualdade incondicional entre os seus membros. Durante a modernização de suas instituições, o processo de expansão do mercado e da industrialização capitalista, nas modernidades periféricas criou-se uma massa de indivíduos subintegrados, uma massa de sub-humanos, com diferenças marcantes em comparação com o moderno lumpemproletariado europeu. Souza chama esse processo de "naturalização da desigualdade" (2006c) e formação da "ralé estrutural" (2009).

\footnotetext{
6 Mais detalhes, em World Christian Data Base.

7 Mais detalhes ver: Arenari, 2013 e Brustlein e Jacob, 2003.

8 Mais detalhes ver: Arenari, 2013 e Brustlein e Jacob, 2003.
} 
Um resultado desse processo é a formação, por um lado, de sociedades mais homogêneas e igualitárias nos países capitalistas centrais, e por outro, as sociedades com as desigualdades sociais e políticas brutais na periferia. Embora existam diferenças de classe nas sociedades capitalistas centrais, essas diferenças estáo relacionadas ao acesso a certos privilégios de classe e estilo de vida. Nas sociedades periféricas, no entanto, a diferenciação de classe ocorre na mesma maneira como nas sociedades centrais, mas com a adição de uma diferença categórica entre as classes de pessoas, visto que alguns indivíduos são considerados muito mais humanos do que outros.

O desfecho desse processo é a formação de uma diferenciação radical entre as classes sociais, formando um abismo quase intransponível entre eles, um universo que é difícil para um europeu do final do século XX imaginar, que vive em uma sociedade que sofreu vários longos processos de equalização. As sociedades modernas periféricas da América Latina são como o terceiro excluído nas análises sociológicas tradicionais: estas sociedades são desconectadas do eixo moderno tradicional e clássico. Eles não são nem as sociedades tradicionais, nem a modernidade clássica, mas também elas não são sociedades modernas incompletas (como postulado pela visão evolucionista); elas são, em vez disso, as sociedades periféricas completas. E as características estruturais dessa sociedade que estão intrinsicamente ligadas ao Pentecostalismo se refere à reunião de dois aspectos: um alto grau de desigualdade e um forte discurso de mobilidade social com modelos individuais de ascensão, essas serão as matérias-primas mais caras à expansão do pentecostalismo.

Em sequência, devemos notar que grande parte da riqueza conceitual do pensamento weberiano em sua sociologia da religião é montada a partir de oposições binárias, muitas delas relacionadas ao tipo de vida tradicional em oposição ao tipo de vida moderno. Assim, Weber (1988) expóe que os estratos sociais do campo mantêm uma relação de total dependência frente à natureza se os compararmos com os estratos urbanos, sobretudo os estratos urbanos modernos, que detêm uma relativa independência em relação à natureza. Se por um lado os comerciantes citadinos vivem em um universo artificial e controlado que é a urbe, exercendo uma atividade econômica contínua que lhes exigem cálculos que oferecem previsibilidade e garante-lhes uma relativa segurança frente às intempéries da natureza, os camponeses estão sujeitos a 
todo tipo de acontecimento que ordinariamente estão aquém do seu controle. Além de estarem submetidos a uma atividade sazonal imposta pela natureza, dependem da ação de forças que náo controlam, nem conhecem, tais como a chuva ou a tempestade, a geada ou a seca, as pragas, enchentes etc. Enquanto o artesáo prevê o tempo final de confecção do seu produto, que depende basicamente apenas do seu trabalho, o agricultor se depara e depende do mistério insondável do nascimento e do crescimento dos organismos.

Em virtude disso, segundo Weber (1988), dois aspectos se destacam na configuração da ação típica dos estratos camponeses. Primeiramente no que se refere à impossibilidade da elaboração ou compreensão de grandes sistemas que envolvem metas de longo prazo, como a salvação da alma em um mundo transcendente a este em que vivemos. As preocupaçóes dos estratos camponeses estão voltadas principalmente para a produção do sustento imediato do qual as garantias de obtenção detêm pouca previsibilidade, enclausurando-lhes em um círculo fechado de metas de curtíssimo prazo, cujo aqui e agora é o único horizonte possível. Por consequência, as forças que, segundo suas interpretações, controlam a natureza (espíritos, deuses, demônios) são alvo de ações coatoras ou barganhas que visam à obtenção de metas imediatas relativas à saúde e riqueza. $\mathrm{O}$ outro aspecto que se destaca é a ausência de uma técnica desencantada no trato com a natureza. Não há uma diferenciação entre técnica e magia, uma vez que a ação mágica é a única “técnica” para coagir as forças da natureza. A dependência absoluta da natureza e a não compreensão racional de seus processos a transforma em um universo misterioso e encantado, em que a magia torna-se a forma cognitivamente acessível de intervenção.

Todos estes exemplos revelam um traço estrutural da tese weberiana a respeito do desenvolvimento religioso, a oposição campo versus cidade. A ruptura ocorrida com o surgimento e desenvolvimento das cidades marca o aparecimento de novos estratos sociais, de uma nova geografia e, por conseguinte, uma nova forma de religiosidade. São os estratos sociais urbanos que permitiram o surgimento de elites especializadas (sacerdotais) que inauguraram uma nova forma de bens de salvação e, conseguintemente, do controle desses bens.

Tendo isso em mente, quando olhamos para a modernidade periférica vemos a eclosáo de novos estratos sociais, de uma nova geografia e, por conseguinte, uma nova forma de religiosidade. E tudo isto está relacionado à noção de 
periferia urbana e aos tipos sociais gerados nela. Estes são um terceiro excluído da teoria social clássica, não são nem os modernos clássicos, nem os da sociedade tradicional, como sempre foram confundidos. O Pentecostalismo é a religião de novo tipo social na história.

Podemos perceber como o discurso da então nova religiáo surgida nos E.U.A. nos finais do século XIX se direcionou para atender às carências e dramas sociais específicos dos recém- chegados ao mundo urbano das grandes cidades norte-americanas, àqueles que habitavam a periferia destas cidades, excluídos: social, econômico e etnicamente do núcleo daquela sociedade. Este mesmo drama social serviu de base para o desenvolvimento do pentecostalismo na América Latina, e, sobretudo, no Brasil. Neste país, uma massa gigantesca de excluídos, também habitante da periferia urbana, (o que atesta a característica moderna destes setores - não tradicional) encontrou no pentecostalismo as promessas de respostas aos seus dramas, especialmente a ansiedade de se integrar a um mundo que não faziam parte. Tal integração se daria por intermédio da promessa contida na modernidade de ascensão social.

A religiosidade pentecostal está diretamente relacionada com o surgimento e desenvolvimento desse novo tipo social na história do capitalismo. O pentecostalismo tornou-se a expressão religiosa por excelência de uma classe social com maior presença numérica em sociedades periféricas, ou seja, a massa de trabalhadores excluídos da expansão capitalista na periferia de seu sistema. Em outras palavras, o pentecostalismo pode ser entendido em traços largos como expressão religiosa que está ligada a uma nova classe ou grande grupo social.

Como resultado dessa hipótese sugere-se que o pentecostalismo se tornou adaptado como a religião das classes dominadas do capitalismo periférico, de tal forma que não só assimilou o modelo religioso das classes dominadas à estrutura do cristianismo mas também recriou facetas marcantes deste tipo de religiosidade. Deve ser lembrado que o pentecostalismos se estabeleceu em um local social específico, e procurou dar respostas religiosas para o drama social coletivo desta nova classe social.

\section{I A promessa de salvação para uma nova classe na história}

Outro elemento de significativa importância na investigação weberiana a respeito do entendimento de alguma religiosidade específica se refere à 
questão sobre a natureza da promessa de salvação posta pela religiaao em questão. $\mathrm{O}$ modelo soteriológico de uma determinada religião está estritamente relacionado às ansiedades e aos dramas coletivos vivenciados por um grupo específico. A pergunta referente ao que este Deus promete, e conseguintemente o que o fiel espera do seu Deus, nos lança no coração dos desafios enfrentados pelo grupo social. Assim, a título de exemplo, percebemos que o Deus de Israel no judaísmo antigo tem como principal promessa o oferecimento de supremacia militar para seu povo, o que vem a calhar para um Estado-Nação deveras pequeno, rodeado historicamente e eventualmente conquistado por grandes potências imperiais como o a Assíria e o Egito. A promessa desse Deus revela as ansiedades e os dramas coletivos de sua gente, o que neste caso era a necessidade de garantias de estabilidade e controle de um determinado território. Tais elementos se confirmam na exaltação de figura de Davi, um herói militar conquistador, como o principal símbolo de Israel, sua figura exerce o papel de redentor dos sofrimentos coletivos.

No caso do Pentecostalismo e suas principais variações, o modelo soteriológico é desenvolvido em consonância com o desenvolvimento da sociedade moderna capitalista. $\mathrm{O}$ pentecostalismo toma para si, via linguagem religiosa, a realizaçáo das principais promessas modernas que náo se efetivaram para uma parcela significativa da população. Para além de confortos psicológicos oferecidos por quase todas as religióes, as noções de inclusão (o valor moderno de igualdade), ascensão social (mobilidade) e modelos devida individual (individualismo) aparecem como o pano de fundo das promessas salvíficas do pentecostalismo. Desenvolve-se, desse modo, um modelo de salvação intramundana em que a força de Deus se confirma na vida cotidiana e na promoção das promessas modernas para uma gente que a modernidade não integrou plenamente. Os subintegrados na vida social, econômica e nos padróes étnicos das primeiras expansóes da sociedade moderna encontraram no pentecostalismo um discurso que atendesse a seus dramas e a suas ansiedades coletivas. Nisto, o pentecostalismo se tornou o cristianismo dos negros e mestiços, dos pobres e todos os outros que se sentiam deslocados naquele mundo em que viviam, mas sabiam que não faziam parte. Em outras palavras, podemos afirmar que essas novas religiosidades são as respostas religiosas para os novos desafios e as demandas sociais enfrentadas pelos novos grupos sociais. Nessa linha de raciocínio sobre o pentecostalismo, a posição social dos indivíduos na 
sociedade é mais importante do que a sua origem cultural, ou seja, a condição de ex-escravo ou subintegrados na periferia urbana desempenha um papel mais importante do que um passado supostamente comum na África.

Com o crescimento e expansão da ideologia do consumo como eixo central das sociedades modernas, tal como nos conta Zigmund Bauman em suas obras recentes, o pentecostalismo continua a prometer o acesso a essas promessas via discurso mágico-religioso.

A profecia exemplar de alguns profetas do pentecostalismo confirma essa vocação específica desse modelo de religiosidade. Isso se mostra seja na vida de seu mitológico fundador, Willian Seymour, como também na vida de um dos profetas do Neopentecostalismo, o Bispo Edir Macedo. Ambos incorporaram (fazem virar carne e osso) as promessas que lançam aos seus fiéis.

William Seymour era um homem negro, filho de ex-escravos. Na verdade, ele passou por várias religióes antes de se tornar o líder de um modelo muito específico de religiosidade. Ele nasceu na Louisiana e foi batizado na Igreja Católica. Como um adolescente, tornou-se um Batista, e aos 25 anos ele se juntou a uma congregação negra da Igreja Metodista Episcopal. Ao mudar-se para Houston, ele se juntou a uma igreja do movimento Santidade. Nesta época, os Estados Unidos náo estava apenas passando por uma intensa migração das zonas rurais para as zonas urbanas, mas também estava passando por um intenso fluxo de imigrantes pobres da Europa. Estes movimentos criaram uma massa de moradores da cidade que não tinham sido totalmente incorporados à vida urbana, criando uma imensa periferia, e muitas dessas pessoas formariam a base dos fiéis da nova religiosidade idealizado por Seymour (CAMPOS, 2005).

O profeta "sentiu na pele" a dureza e crueldade do apartheid norte-americano, e, certamente, essa experiência o afetou profundamente. Seymour sonhou com uma sociedade sem barreiras raciais, e esperava que o Espírito Santo faria isso no culto ao Azusa Street. Do ponto de vista social, ele buscou construir um espaço onde os setores marginalizados da sociedade não sentiriam a pressão dos mecanismos de segregação social e étnica que lhes eram impostos. Em seu culto, os preconceitos de classe, raça e gêneros se desfaziam no caldeirão emocional. Ele foi capaz de oferecer ao público o alívio emocional que mais queriam. Como um profeta exemplar, ele canaliza os sentimentos 
em sua trajetória, e oferece respostas para seus dramas e angústias pessoais e sociais mais profundos.

No período inicial, a base social do Pentecostalismo foi um aspecto importante do seu desenvolvimento. Podemos identificar que esta vocaçáo social específica nesta religião marcou sua trajetória seguinte, onde alguns estudiosos interpretaram o Pentecostalismo como uma "religião de deserdados", ou seitas de minorias (CORTEN, 1996; CAMPOS, 2005).

O Bispo Edir Macedo - mais conhecido de nós, brasileiros - incorporou o discurso de ascensão financeira e política muito presente no neopentecostalismo e na teologia da prosperidade que marca esta religiosidade contemporânea. Em um período de 30 a 40 anos, o Bispo, que então era um pobre brasileiro da periferia do Rio de Janeiro, tornou-se um dos empresários mais bem-sucedido do país e também um dos homens mais poderosos do Brasil, controlando a segunda maior rede de televisão, uma bancada poderosa de políticos e transformando sua igreja em uma gigante do mercado religioso mundial, exercendo um poder significativo em alguns outros países e continentes.

No caso brasileiro, não concidentemente o maior país pentecostal do mundo, a presença de uma massa de indivíduos excluídos ansiosos para a inclusão social, e uma forte tradição de religiosidade mágica na cultura popular, estabeleceu uma base sólida e fértil para a expansão de uma religiosidade neoentecostal, que trouxe respostas modernas às expectativas modernas. Portanto, o Pentecostalismo e sua variedade mais dinâmico; já o Neopentecostalismo é uma religiosidade que foi adaptada e produzida dentro dessas expectativas novas e puramente modernas. Em outras palavras, ele prometeu uma inclusão muito desejada e ascensão de acordo com uma promessa terrena, não um sobrenatural em um paraíso post-mortem e resultante de uma vida inteira de sacrifícios.

\section{Notas a respeito da cognição religiosa e o pentecostalismo}

Como últimos apontamentos, citarei alguns aspectos cognitivos que também devem ser levados em conta em uma perspectiva weberiana, isto é, em que medida disposiçóes cognitivas de classe, como também, modelos religiosos 
cognitivos são construídos e reconstruídos sócio historicamente. Neste caso, o aspecto da cognição mágica presente no pentecostalismo é digno de nota.

A América Latina como um todo, assim como o Japão, é uma sociedade que incorporou uma série de valores e instituiçóes ocidentais modernas, sem fazer uma ruptura radical com a magia. No caso da América Latina, essa seletividade de incorporação de valores ocidentais modernos também se manifesta entre as classes em que a difusão da cultura mágica aparece mais forte, ou seja, nas classes mais baixas.

O que deve ser enfatizado aqui é que a possibilidade de conduta racional da ação não foi um pressuposto universal, esteve restrito a determinados segmentos da modernidade. Em muitos outros lugares, especialmente nas modernidades periféricas, uma grande proporção da população nunca experimentou essa ruptura radical com a incorporação do modelo cognitivo da representação racional com o mundo - a magia sempre foi uma constante para eles.

Assim, enquanto a cognição religiosa mágica parece ser uma novidade em países centrais e de classe média global, no retorno das religióes, essa faceta nunca deixou de existir na periferia. Ela agora é apresentada apenas como uma segunda onda de expansão, uma versão renovada e remodelada de magia antiga.

Assim, podemos concluir que, sem a presença da não ruptura com o modelo cognitivo de religiosidade mágica, as possibilidades de sucesso para o pentecostalismo e neopentecostalismo seria limitada no Brasil; uma vez que tal afinidade do discurso religioso foi certamente um aspecto fundamental para o sucesso dessa religiosidade no país. A conversão ao pentecostalismo não representa uma ruptura radical com o passado religioso dos fiéis, como as divindades do universo religioso do sincretismo mágico afro-católico continuam a existir com pequenas alteraçóes na vida mágico-religiosa pentecostal. Além disso, o substrato da cognição religiosa mágica nunca deixou de existir após a conversão, isto é, a possibilidade de intervenção divina e sobrenatural nos problemas básicos da vida cotidiana em qualquer momento ou situação.

Dentro desse processo de desenvolvimento, o Pentecostalismo e, especialmente Neopentecostalismo, foi a corrente religiosa que incorporou e liderou a expansão de uma magia renovada e adaptada para as periferias urbanas, e 
distinta da velha religiosidade mágica da vida rural. Como eles migraram do campo para as cidades, os camponeses pobres imersos no sincretismo mágico afro-católico - em que santos e orixás compartilhavam o mesmo espaço - converteram-se ao pentecostalismo, mas mantiveram-se em seu universo mágico em que Deus intervém no mundo diariamente operando "milagres" relacionados à saúde, à vida afetiva/sexual e financeira/profissional.

No entanto, esse tipo de magia renovada, que herdou a velha tradição religiosa brasileira, também foi capaz de adaptar as suas promessas para a nova realidade social de seu público de fiéis. Sua principal promessa é a ascensão social e, consequentemente, mas não secundariamente, o acesso ao mercado de consumo. Nesse novo mundo urbano, de rápida modernização e aumento da hegemonia do discurso capitalista, o pentecostalismo oferece meios mágico-religiosos para uma populaçáo excluída dos benefícios das promessas capitalistas para ter acesso a esse universo.

Tudo isso ajuda a compreender a gênese sociorreligiosa de uma naçáo onde o pentecostalismo tornou-se um exemplo do modelo de expansão de sua religiosidade, detalhando o desenvolvimento de fatores que mais contribuíram para o seu sucesso. Houve uma socializaçáo religiosa dessa massa imersa em uma linguagem contaminada pela magia, resultando em uma religiosidade (neopentecostalismo), que, por sua vez, criou centros de serviços mágicos que prometem a seus seguidores, por meio de uma ação divina (ou coerção desta ação), o acesso ao mundo de maravilhas imaginadas na sociedade capitalista que ainda não puderam alcançar.

\section{Referências}

ANDERSON, A. The gospel and culture in Pentecostal mission in the third world. 9th Conference of the European Pentecostal Charismatic Research Association, Missions Academy, University of Hamburg, Germany, july 1999.

BURITY, J. A. Cultura e Identidade no campo religioso. Rio de Janeiro: UFRRJ, 1997.

BURGESS, S. M.; MCGEE, G. B. (Ed.). Dictionary of Pentecostal and Charismatic Movements. 7. impr. Grand Rapids, Michigan: Zondervan Publishing House, 1995.

CAMPOS, L. S. As origens norte-americanas do pentecostalismo brasileiro: Observaçóes sobre uma relação ainda pouco avaliada. Revista USP, São Paulo, n. 67, p. 100-115, set./nov. 2005. 
CORTEN, A. Os Pobres e o Espírito Santo: o pentecostalismo no Brasil. Petrópolis: Vozes, 1996.

FRESTON, P. Evangelicals and Politics in Asia, Africa and Latin America. Cambridge, Cambridge University Press, 2001.

HALL, S. Old and New Identities, Old and New Ethnicities. In: KING, A. D. (Ed.). Culture, Globalization, and the World-System. Basingstoke: State University of New York, 1991. p. 41-68.

HOLLENWEGER, W. J. The Pentecostals. London: SCM Press, 1972.

LUHMANN, N. Funktion der Religion. Frankfurt: Suhrkamp, 1977.

The Pentecostals: The World Their Parish. Oxford: Blackwell, 2002.

ROLIM, F. C. Pentecostalismo: Brasil e América Latina. Série desafios da religião do povo. VII. Petrópolis: Vozes, 1995.

SOUZA, J. (Org.). A Invisibilidade da Desigualdade Brasileira. 1. ed. Belo Horizonte: UFMG, 2006c.

. A Ralé Brasileira: quem é e como vive. Rio de Janeiro: Record, 2009.

. Os batalhadores brasileiros: outra visão sobre a nova classe média. Belo Horizonte:

Ed. UFMG, 2010.

WEBER, M. Wirtschaft und Gesellschaft. Tübingen, 1976.

Gesammmelte Ausätze zur Religionssoziologie. Tübingen, 1988.

Essays in Sociology. New York: Routlegde, 2009. 


\section{An outline of a Weberian program for understanding Pentecostalism}

\section{Abstract}

I intend to map the historical and ideological impediments and also the possibilities of building a theoretical and empirical research program organized from Max Weber's ideas about a religious phenomenon which the author did not witnessed, namely, Pentecostalism. In view of this goal I will construct my arguments into four distinct areas: (1) "Pentecostalism Analysis Mainstream and the rejection of the Weberian perspective"; (2) "Max Weber and Materialism"; (3) "Pentecostalism and Capitalism"; (4) "The promise of salvation for a new class in history" and finally (5) "Notes about religious cognition and Pentecostalism". At the end of this article I do not claim to present a final thesis on Pentecostalism, but rather a set of well solid assumptions, tom old a research program to be developed and tested.

Keywords: Max Weber. Pentecostalism. Sociology of Religion.

Recebido em: 20/11/2016.

Aprovado em: 09/02/2017. 